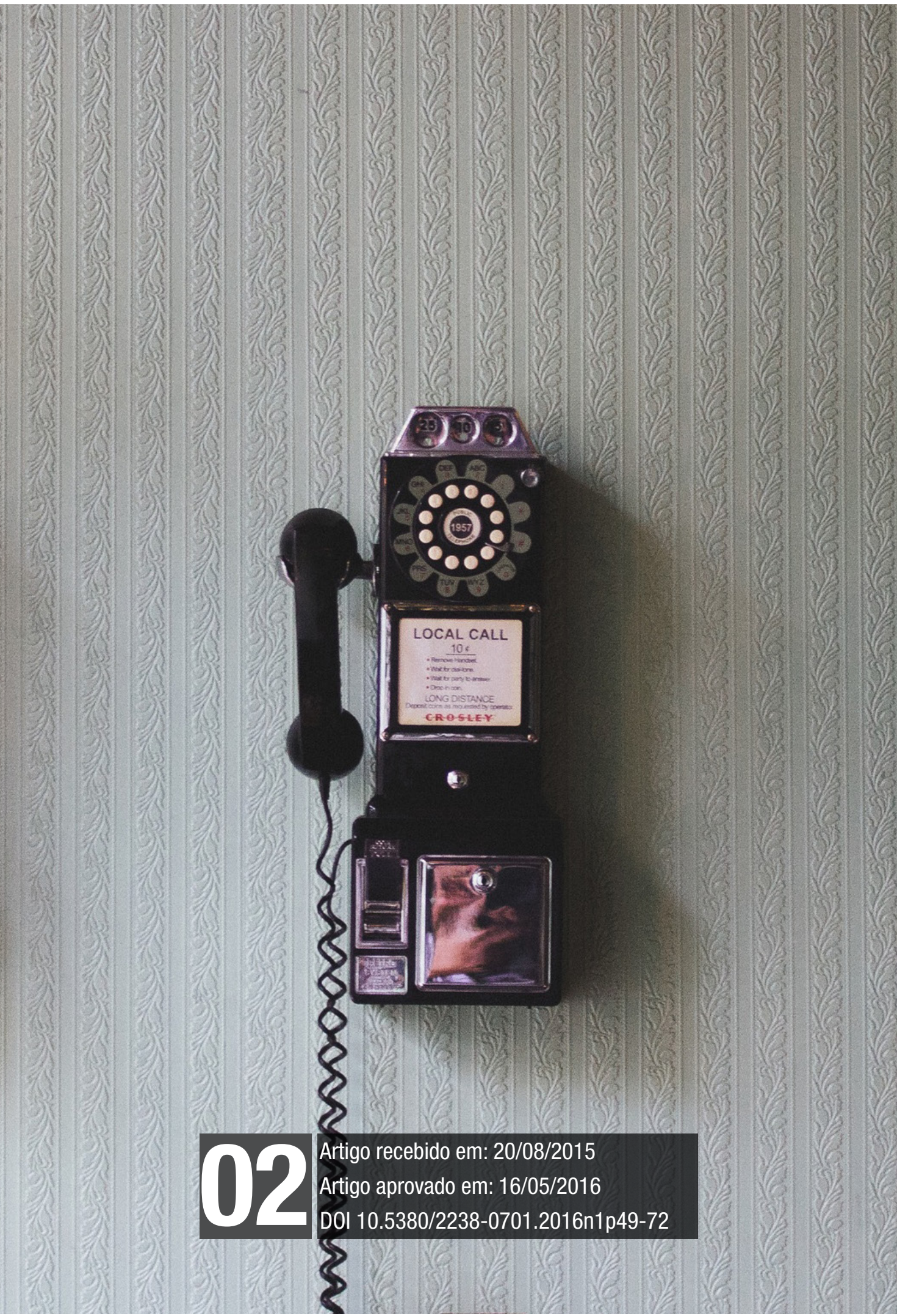


Mídia Pública. Brasil. Comunicação. Públicos.

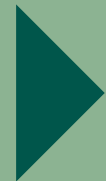




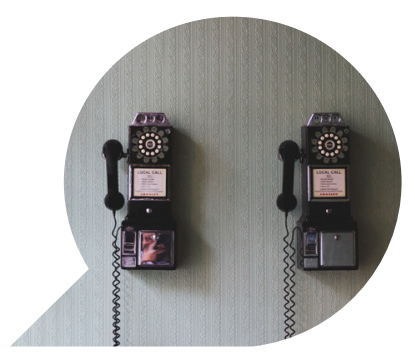

\title{
Mídia pública no Brasil: do estatal ao não-comercial
}

\author{
Public media in Brazil: from state to non-commercial \\ Medios de comunicación públicos en Brasil: \\ desde el estado a non commercial
}

GUILHERME CARVALHO *

Resumo: Propõe-se uma releitura conceitual de "mídia pública" no Brasil, considerando três elementos preliminares para a construção desse artigo: a produção acadêmica ligada diretamente ao tema considerando as análises de diferentes casos nacionais, o "empréstimo" da teoria sobre a esfera pública e a esfera privada de Habermas. Consideramos como terceiro elemento as leituras sobre a realidade política brasileira. A partir da revisão bibliográfica e da teorização do tema, elaboramos o que consideramos como uma proposta conceitual para mídia pública no Brasil que procura uma definição mais abrangente, partindo de questões estruturais.

Palavras-chave: Mídia pública; Brasil; Comunicação; Públicos.

\footnotetext{
* Doutor em Sociologia pela Universidade Estadual Paulista (Unesp), mestre em Sociologia pela Universidade Federal do Paraná (UFPR) e graduado em Jornalismo pela Universidade Estadual de Ponta Grossa (UEPG). É professor de Jornalismo do Centro Universitário Internacional (Uninter) e professor substituto do Departamento de Comunicação da Universidade Federal do Paraná (UFPR).
} 
Abstract: A conceptual rereading of "public media" in Brazil is being proposed here, wherein two primary elements make up the construction of this paper: the academic production directly linked to the subject and that of the analysis of different national cases, and using the public and private sphere theories constructed by Habermas. The third element of this analysis comes from the Brazilian political reality. From both the literature review and from theorizing the theme, a conceptual proposal for "public media" in Brazil has been developed in this paper. This proposal seeks a broader definition that starts based on structural issues.

Keywords: Public media; Brazil; Communication; Publics.

Resumen: Se propone una reinterpretación del concepto de "medios públicos" en Brasil, teniendo en cuenta tres elementos principales para la construcción de este artículo: la producción académica directamente relacionada con el tema y los del análisis de diferentes casos nacionales, el "préstamo" de la teoría en el alcance público y la esfera privada de Habermas. Consideramos en cuarto elemento las lecturas de la realidad política brasileña. De la revisión de la literatura y el tema de la teoría, hemos desarrollado lo que consideramos como una propuesta conceptual para los medios de comunicación públicos en Brasil en busca de una definición más amplia, desde los problemas estructurales.

Palabras clave: Medios de comunicación públicos; Brasil, Comunicación; Públicos. 


\section{Introdução}

O Brasil vive um momento ímpar no que diz respeito aos meios de comunicação ditos públicos, geralmente relegados a um espaço de pouca relevância no cenário nacional. Nos últimos anos, tem se estruturado uma política de reorganização do sistema prevendo a criação de uma rede de televisão que possibilite a exibição de uma programação diferenciada em relação aos meios de comunicação comerciais, marcadamente hegemônicos no país - se considerarmos os índices de audiência, a capacidade de influência na opinião das pessoas e os aspectos estruturais, tecnológicos e financeiros que refletem diretamente no oferecimento de conteúdos com qualidade técnica superiores em relação à comunicação pública.

A percepção crítica sobre a realidade e as ações governamentais têm provocado várias iniciativas que visam uma reorganização do campo público na área. Em 1998, algumas das principais emissoras ligadas diretamente a governos estaduais do Brasil criaram a Associação Brasileira das Emissoras Públicas, Educativas e Culturais (ABEPEC) ${ }^{1}$. Em 2006, realizou-se o "I Fórum Nacional de Tv's Públicas", a partir do qual foi publicado o "Diagnóstico do Campo Público de Televisão”, organizado pelo Ministério da Cultura. O documento traça a política do Governo Federal para a constituição de uma rede nacional pública que tem como principal motor a Empresa Brasil de Comunicação (EBC). Recentemente, o tema também passou a fazer parte das pautas de organizações ligadas à luta pela democratização dos meios de comunicação como o Fórum Nacional de Democratização da Comunicação (FNDC) e a Federação Nacional dos Jornalistas (Fenaj).

No campo das ciências, verifica-se a consolidação da temática e do objeto de estudo a partir da constituição de redes de pesquisa ligadas a universidades públicas, como a Universidade Federal de Santa Catarina (UFSC), Universidade de Brasília (UnB) e Universidade Federal de Juiz de Fora (UFJF). Destaca-se a criação do Observatório da Radiodifusão Pública na América Latina, em 2011, além de uma série de publicações recentes sobre o assunto. Também é possível encontrar o trabalho desenvolvido por coletivos como o Intervozes, que tem acompanhado o desenvolvimento das emissoras públicas do Brasil comparando estas emissoras a realidades de outros países.

\footnotetext{
${ }^{1} \mathrm{~A}$ associação foi criada com o objetivo de fundar uma rede nacional que permitisse o compartilhamento de conteúdos entre as emissoras públicas, de modo que se constituísse uma programação comum entre todas.
} 
Também na imprensa brasileira em geral é possível verificar um crescimento de reportagens e artigos de opinião sobre o assunto. As abordagens muitas vezes críticas ressaltam o investimento estatal em emissoras públicas e a tentativa de controle de informações pelo governo.

Expressa-se, portanto, uma preocupação institucional em diversos campos de relevância social do Brasil que contribuem para repensar o que vem sendo desenvolvido sobre meios de comunicação de massa por meio de radiodifusão, políticas públicas promovidas por governos e emissoras ligadas direta ou indiretamente a União, Estados ou Municípios.

Esta preocupação está ligada diretamente ao debate acadêmico e político que vem sendo feito no país quase 50 anos depois do início de políticas governamentais em âmbito federal para a construção das bases do sistema de comunicação do país. Conforme Lopes (2001), somente em meados dos anos 1970, sob influência marxista da Escola de Frankfurt, é que são percebidos estudos culturais e em comunicação que apontam os riscos ao direito à liberdade de informação, a partir da compreensão do sistema privado dos meios de comunicação como parte da estrutura da indústria cultural, opondo-se ao paradigma funcionalista promovido pelo Centro Internacional de Estudios Superiores de Comunicación para América Latina (Ciespal).

Porém, a leitura crítica sobre os meios de comunicação no Brasil e muitas vezes militante praticamente desconsiderou a questão dos meios não comerciais durante a maior parte desses últimos 30 anos. A partir dos anos 2000, a questão do direito à comunicação pública no Brasil parece ter maior espaço, de modo a contribuir para repensar o sistema considerando alternativas ao sistema comercial.

Este debate tem como desafio, portanto, a busca pelo amadurecimento teórico-conceitual, aliado ao trabalho empírico para observação da realidade e estabelecimento de uma práxis capaz de contribuir para amadurecer a questão na sociedade brasileira a partir das problemáticas a serem identificadas.

Nesse sentido, propomos uma releitura conceitual de "comunicação pública", considerando três elementos preliminares para a construção desse artigo: a produção acadêmica ligada diretamente ao tema e que parte das análises de diferentes casos nacionais; $o$ "empréstimo" da teoria sobre a esfera pública e a esfera privada de Habermas. A compreensão dos conceitos de público e privado, no 
entanto, precisam considerar os diferentes contextos para evitar os preconceitos que uma leitura baseada em uma outra realidade possa causar. Assim, consideramos como terceiro elemento as leituras sobre a realidade política brasileira.

A partir da revisão bibliográfica e da teorização do tema, elaboramos o que consideramos como uma proposta conceitual para "mídia pública" no Brasil. Este artigo é parte de uma pesquisa iniciada em 2014 sobre mídia pública no Brasil, tendo gerado outros resultados e que ainda se encontra em andamento.

\section{Estado como representação do público e comunicação}

Baseado na ideologia das oportunidades iguais e do direito às liberdades individuais, o regime de governo dito democrático foi fundamental para dar legitimidade suficiente ao Estado de modo a concentrar poder suficiente para se impor como autoridade para dirimir os conflitos resultantes das diferenças de interesse na sociedade. Assim, quanto mais coesa uma sociedade, maior a representatividade do Estado nas relações sociais ou quanto mais representativo é o Estado, menor o grau de conflitos.

Ideologias à parte, o princípio de democracia em um sistema liberal regulado pelo Estado cumpre um papel importante na manutenção do status quo. Sartori (2008) descreve o conceito de democracia apontando três aspectos distintos: "En primer lugar, la democracia es un principio de legitimidad. En segundo lugar, la democracia es un sistema político llamado a resolver problemas de ejercicio (no unicamente de titularidad) del poder. En tercer lugar, la democracia es un ideal" (p. 29)2. Esta descrição sugere uma crítica sobre os sistemas de governo e, sobretudo, a respeito da crença que é depositada pela sociedade sobre este modo de governo. Ao estabelecer os princípios de concorrência, o sistema democrático aparenta um sentido de igualdade social, assegurando a aceitação geral sobre o modo de governo.

Os espaços disponíveis para a competição no sistema democrático estão delimitados de acordo com certas regras que incluem o acesso às decisões de governo por meio de agentes intermediadores entre o povo e os poderes constitucionais. O sucesso do regime democrático decorre

\footnotetext{
2 “Em primeiro lugar, a democracia é um princípio de legitimidade. Em segundo lugar, a democracia é um sistema político utilizado para resolver problemas de exercício (não unicamente de titularidade) do poder. Em terceiro lugar, a democracia é um ideal".
} 
da capacidade de assimilar as organizações paralelas da sociedade civil como representantes de uma parcela da população, com capacidade de mobilização e de organização dos trabalhadores (SARTORI, 2008).

Sartori (2008) entende democracia como um princípio de legitimidade, um sistema político utilizado para resolver problemas de exercício de poder. Mas, segundo ele, trata-se também de um ideal fundamentado na noção de que o poder pertence ao povo que exerce esse poder por meio de seus representantes eleitos. Para o sentido de democracia representativa moderna, deve-se ter em mente uma concepção de exercício de poder indireto, ou seja, realizado por meio de mediações, mas que não é exercido de maneira isenta ou neutra. O Estado, assim como outras instituições da sociedade, são ambos movidos por interesses particulares de grupos com força de pressão na sociedade, para que possam impor suas vontades sobre os demais.

Habermas (1984) mostra que na Idade Média a constituição da esfera pública não era possível porque as formas de representatividade pública não eram debatidas, eram impostas. O rei representava o povo como um poder superior. Esta condição possibilitou à igreja se constituir também como um espaço de representatividade que se confundia com a soberania do rei, na qual o debate sobre o público não cabia ao povo, mas a uma corte.

A Era Moderna torna o público e privado antagônicos ao retirar dos dirigentes do Estado o poder que agora a vida privada exigia. No desenvolvimento das relações de troca mercantil na qual se constitui o Estado moderno, modificam-se as relações de poder na sociedade. O que se observa, então, é a polarização não mais da vida pública e da vida privada, mas a diferença entre o "público" como o contingente populacional que compõem a sociedade e o "público" que diz respeito aos aspectos coletivos administrados e representados pelo Estado.

O Estado, representado pelos governantes, deve, portanto, servir ao indivíduo em seus aspectos públicos e privados.

A esfera pública burguesa pode ser entendida inicialmente como a esfera das pessoas privadas reunidas em um público; elas reivindicam esta esfera pública regulamentada pela autoridade, mas diretamente contra a própria autoridade, a fim de discutir com ela as leis gerais da troca na esfera fundamentalmente privada, mas publicamente relevante, as leis do intercâmbio de mercadorias e do trabalho social. (HABERMAS, 1984, p. 42) 
A atividade econômica passa a ser privatizada no momento em que este poder que emana do público consegue impor prioridades aos administradores que interessam a uma relação de trocas regida pelo capitalismo, em nome do interesse de todos. Assim, a esfera pública constituída pelos interesses de alguns grupos específicos passa a determinar a esfera privada.

O fato de a constituição desta sociedade basear-se sobre as relações de troca consolida o direito à propriedade privada, que é resultado da ideia de autonomia do indivíduo no qual a vida privada se estabelece sobre uma esfera pública determinada por estas relações. Esse processo contou com um importante agente. A construção das relações sociais na Era Moderna teve como principal motor os meios de comunicação de massa. "A redução da representatividade pública que ocorre com a midiatização das autoridades estamentais através dos senhores feudais cede espaço a uma outra esfera, que é ligada à expressão esfera pública no sentido moderno: a esfera do poder público" (HABERMAS, 1984, p. 31).

O público, em essência, liga-se ao interesse coletivo resultante das demandas da vida privada. Nesse sentido, ele significa aquilo que deve ser feito coletivamente para resguardar os interesses de todos, ou o bem comum. Mas em sociedades onde o valor da liberdade individual faz emergir os interesses privados como interesses distintos entre os indivíduos, o poder que se exerce sobre a sociedade não pode ser encarado como "público", no sentido de que se exerce sem interesses privados. Ele toma um caráter coletivo por meio de mecanismos de legitimação que permitem a representação política por meio das instituições, mas atua segundo uma lógica privada.

Pelo ideal democrático, o meio de comunicação deveria ser a expressão dos interesses gerais e específicos da sociedade, de modo a garantir a representatividade de todos. Os meios públicos deveriam ser aqueles que promoveriam o espaço para o debate que possibilitaria uma arena de argumentações e ideias que permitissem uma compreensão melhor sobre a realidade e, portanto, um maior senso de justiça.

Rodrigues (1994) aponta que o avanço tecnológico dos meios de comunicação implica em um imperativo ético e uma urgência política sobre a necessidade do indivíduo se comunicar. A aceleração desse processo implica em uma constante defesa da individualidade, acima da racionalidade. Nesse sentido, vivemos uma era de ideologia co- 
municacional que constrói um novo tipo de racionalidade. Ela é crítica à própria modernidade, por outro lado, se liga a fundamentos da própria modernidade. Expressa a defesa dos interesses individuais, é o símbolo da liberdade individual. Por isso, a dificuldade em regular a comunicação. A racionalidade moderna pressupõe que a liberdade individual deve ser guiada pelo direito à informação. É o que permite ao indivíduo guiar suas ações por meio da maior quantidade de relatos possíveis sobre a experiência humana. A construção do mundo real pelo indivíduo, a partir de um processo mediado por tecnologias da comunicação está, portanto, sustentado pelo uso técnico racional dos meios com interesses particulares.

Esse, portanto, é o drama da comunicação em qualquer sociedade. Ele é expressão da liberdade, ao mesmo tempo em que se legitima como instrumento ideológico.

O público, portanto, refere-se não a ideia de tornar público, tampouco ao povo, mas "Aquilo que se torna público, que é público, pressupõe, então, a existência de interesses universalizados - com imposição de responsabilidade para o conjunto da sociedade - através do processo de sua inserção como direitos no seio do Estado." (LAVALLE, 2001, p. 79). Afinal, na ideologia do Estado moderno, esta instituição é a principal responsável por canalizar as forças sociais em favor da garantia de direitos iguais, expressos pelo princípio da defesa dos interesses públicos.

Os meios de comunicação têm um papel fundamental nesse debate na medida em que se tornam espaços de disputa de poder e em que são legitimados com vistas à institucionalização das ações humanas. Encontramos, então, o conceito de "espaço público" como aquele que

é determinado pela existência de um sistema de comunicação com sentido público, quer dizer, de processos que fundem a um só tempo e sob uma mesma lógica específica a transmissão e a produção de significados econômica, política e socialmente relevantes (LAVALLE, 2001, p.83).

Em outros termos, significa que a manutenção do interesse público em uma sociedade está condicionada à capacidade do Estado em garantir o "espaço" de ideias e liberdade de opinião para que o cidadão se sinta pertencente. Assim, a comunicação teria um papel fundamental na construção de identidades nacionais. 


\section{O drama do “público” no Brasil}

$\mathrm{Na}$ literatura científica brasileira o que se observa são percepções otimistas sobre este tema, apesar das contundentes críticas ao sistema de comunicação do país. Esse parece o efeito de algumas iniciativas, sobretudo, governamentais, que parecem reacender o interesse pelo tema e que prometem uma nova perspectiva para o futuro, como pode ser observado a seguir:

A TV pública é uma janela de acesso estratégico para o contato da população com a mais vasta gama de bens e serviços culturais, constituindo um canal privilegiado para a valorização e a universalização do patrimônio simbólico nacional. A rede de emissoras públicas é uma opção de grande potencial como veículo difusor da produção audiovisual oriunda dos distintos agentes culturais da sociedade, assegurando a expressão de nossa rica diversidade cultural, assegurando a prática da democracia (SENNA, 2006, p. 9).

Quando o espaço público não está assegurado, ou seja, quando ocorre censura ou quando os interesses privados se sobrepõem ao interesse público nos meios de comunicação, há um rompimento das relações de confiança da sociedade. O indivíduo deixa de se reconhecer como cidadão. Enfraquecem os sentimentos de pertencimento e de identidade uma vez que o direito de participação e conhecimento fica prejudicado.

Nesse sentido, o problema está na dificuldade de determinadas sociedades em diferenciarem o interesse público do interesse político. Aquele precisa ser resguardado pelo Estado, enquanto esse é inerente ao Estado, porque as decisões governamentais que são determinadas pelos diversos grupos sociais de um país estão organizadas por meio de partidos e se confundem com a ideia de ação política como sendo aquela restrita ao espaço institucional ou às esferas de poder do Estado.

No cenário brasileiro, o sentimento de pertencimento ou de cuidado com a máquina pública raramente emerge. Assim, a vigilância sobre a atuação de governos em relação à máquina pública acaba sendo exercida com maior cumplicidade entre os que deveriam atuar na fiscalização dos poderes, dificultando o questionamento e a participação social na vida política do país. Em parte, isto se deve à ausência de um senso crítico que pudesse contribuir para que os brasileiros tenham condições de participar da vida política do país, 
porque, desde o início, os meios de comunicação do país estiveram atrelados aos interesses de uma elite privilegiada. $\mathrm{O}$ resultado disso é uma frágil concepção do que é o público para o brasileiro e sobre o papel do Estado, sobretudo como principal agente responsável pela garantia dos espaços de participação do cidadão, perceptível na ausência de reflexões sobre as condições atuais destes meios que não estejam relacionados apenas a aspectos técnicos da produção.

\section{A comunicação pública privatizada}

O conteúdo em debate no espaço público vinculado, portanto, aos meios de comunicação, está filtrado pelos interesses particulares. A sustentação dessas condições se dá por dois fatores que atuam no sentido de concentração de poder nos meios de comunicação. Um é o sistema oligopólico privado que reduz a pluralidade de opiniões e, portanto, dificulta outras leituras da realidade, empobrecendo o espectro de experiências que são fundamentais para a crítica e para a elaboração de alternativas. O outro pode-se entender como um sistema onde a dimensão entre público e privado é nebulosa devido ao esvaziamento do debate sobre o que deve reger os interesses representados pelos governos porque prevalece uma percepção unicamente privada sobre as relações sociais.

No Brasil, o sistema de comunicação consolidou-se tardiamente, antes mesmo de uma lógica competitiva de mercado, diferentemente dos Estados Unidos, onde o sistema se estruturou e se organizou pelo empresariado, ou da Europa, onde o que primeiro se consolidou foram os meios de comunicação estatais. No Brasil, o sistema expandido nacionalmente por satélites e cabos foi financiado pelo Estado porque o empresariado brasileiro não estava em condições de realizar investimentos. "O sistema de redes, condição essencial para o funcionamento da indústria cultural, pressupunha um suporte tecnológico que no Brasil, contrariamente dos Estados Unidos, é resultado de um investimento do Estado" (ORTIZ, 1994, p. 118).

Assim, tem-se naturalizado que o sistema público de comunicação no Brasil deve ser concedido para exploração da iniciativa privada. O Estado é promotor das condições para que se realize uma arena pública de debate - financia e compra tecnologia - mas, naquele período (1960-1970), ao mesmo tempo em que exercia um forte controle por meio da censura aos conteúdos exibidos, concedia a ex- 
ploração do sinal para empresários que demonstravam alinhamento ideológico com o governo militar.

Ortiz (1994) demonstra que o governo tinha um forte interesse na expansão dos meios de comunicação brasileiros para que pudesse promover a integração nacional. À primeira vista, ao receber uma concessão pública para exploração do sinal, qualquer emissora estaria apta a realizar aquilo que o Estado não fez, portanto, deveria atuar como promotor dos interesses públicos e compor um aparente sistema público. Mas a estruturação desse sistema pauta-se, no entanto, pela demanda do consumo e não pela promoção da cultura local ou do popular. Nessas condições, imperam produções que seguem as razões do mercado, legitimadas por perspectiva superficialmente política e nacionalista e que formam uma ideia distorcida para os próprios brasileiros do que é cultura e do que é nação (ORTIZ, 1994).

A ação do Estado em relação aos meios de comunicação ganhou força com a crise econômica de 1973, marcada pela recessão em países periféricos e o questionamento social que se exercia contra os regimes autoritários. $\mathrm{Na}$ emergência de demandas que propunham $\mathrm{o}$ fortalecimento das relações entre os países da América Latina, surge uma proposta de "nova ordem mundial da informação e da comunicação" na qual os meios de comunicação de massa deveriam ser encarados como

fundamentais na mobilização da opinião pública para respaldar as decisões dos dignitários governamentais, principalmente nos regimes democráticos, onde muitas vezes as campanhas orientadas por monopólios de difusão massiva podem seduzir multidões para comportamentos politicamente equivocados, produzindo repercussões que quase sempre inibem a atuação dos governantes ou os induzem a retroagir em questões de evidentes interesses nacional e popular, habilmente manipuladas pelos persuasores profissionais a serviço de grupos privilegiados ou de interesses externos. (MELO, 1989, p. 16)

A comunicação, portanto, passaria a ser encarada como questão de soberania nacional. Não por acaso, a legislação do Brasil, no que diz respeito à comunicação, passa a impedir investimentos estrangeiros em meios de comunicação ${ }^{3}$. O investimento do Estado deveria

\footnotetext{
${ }^{3}$ Contraditoriamente, neste mesmo período, em 1965, a TV Globo firmou um contrato de assistência técnica assinada com o grupo norte-americano Time-Life onde recebeu U\$ 5 milhões, no qual previa uma participação nos lucros da emissora brasileira. 0 acordo foi referendado pelo Governo Federal e a denúncia de inconstitucionalidade arquivada no Congresso Nacional. (SILVA, 1985)
} 
ser destinado para infraestrutura e para produção de conteúdo próprio; tornar-se-ia meio para o desenvolvimento cultural, econômico e social dos países.

Não obstante o sistema nacional de comunicação seja operado pela iniciativa privada, como é o caso da radiodifusão e da imprensa, a presença do aparelho estatal é ostensiva e eficiente, operando setores estratégicos que vão das telecomunicações e da informática até as novas tecnologias de fibras óticas, pacotes de dados, antenas para captação de sinais de satélite. (MELO, 1989, p.35)

Diante da pressão, os governos militares brasileiros garantiriam na lei a existência de canais de rádio e televisão mantidos pelos estados e municípios. Surgem, então, as emissoras "educativas". A lógica dessas emissoras, criadas a partir do Decreto Lei 236, de 28 de fevereiro de 1967, é o da formação de um contingente populacional com baixa escolaridade que pudesse atuar nas cidades grandes do país que viviam um intenso processo de industrialização (VALENTE, 2009). Aparentemente a intenção era preparar o máximo de pessoas possíveis, em menor tempo, para atuar no novo mercado de trabalho que se constituía no país. A iniciativa propunha a substituição da sala de aula para aperfeiçoar alunos e professores. Nesse sentido, não visavam a competição pela audiência. Por outro lado, as "educativas" tinham ainda menor autonomia editorial. Constituíam-se como emissoras dos estados, portanto, estatais, mas com poucas possibilidades de diversificação de conteúdos e pluralidade de opiniões.

A primeira emissora educativa a entrar no ar foi a TV Universitária de Pernambuco, em 1967. Entre 1967 e 1974, surgiram nove emissoras educativas por meio do Decreto-lei 236/67. A lei assinada pelo então presidente Castello Branco, passou a prever dentro do Código Brasileiro de Telecomunicações, criado em 1962, a possibilidade de concessão de canais para União; Estados, Municípios; Universidades; e Fundações, desde que se destinem

à divulgação de programas educacionais, mediante a transmissão de aulas, conferências, palestras e debates. [...] (e considerando que) A televisão educativa não tem caráter comercial, sendo vedada a transmissão de qualquer propaganda, direta ou indiretamente, bem como o patrocínio dos programas transmitidos, mesmo que nenhuma propaganda seja feita através dos mesmos. (DECRETO, 2015) 
Seguindo a política governamental para as rádios e televisões educativas do país, em 1972, o Ministério da Educação (MEC) criou o Programa Nacional de Teleducação (PRONTEL) com o objetivo de coordenar as atividades de teleducação no país. Até o final dos anos 1980, as rádios e televisões educativas contavam com conteúdos inteiramente produzidos sob supervisão do Ministério da Educação, administrado pelo Sistema Nacional de Radiodifusão Educativa (SINRED) (FRADKIN, 2015). Com a revisão da legislação a partir dos anos 1990, as emissoras educativas passaram a operar com maior autonomia em relação ao Governo Federal, mas não em relação aos governantes.

As brechas na legislação, ampliadas pela nova conjuntura que beneficiava os interesses privados, fez com que as emissoras educativas do país herdassem o modelo institucional e voltado ao atendimento de interesses político-partidários, sem que concorressem com os interesses privados. Assim, não era política de Estado constituir emissoras que concorressem em audiência com as emissoras privadas. Ao contrário, as estatais atuavam (e anda atuam em sua maioria) com baixa qualidade de conteúdo e pouca produção própria, relegadas a canais inativos ou com baixíssima audiência.

"O atual modelo descende diretamente do período autoritário, cuja finalidade era assegurar, por meio da imagem eletrônica, a integração nacional no plano do imaginário, deixando de lado o contraditório, a pluralidade, a discordância." (BUCCI, 2015)

O cenário atual expressa fragilidade em relação às condições para a estruturação de um sistema de comunicação voltado para atender aos interesses públicos. O uso das concessões de TV como "moeda de troca” entre o governo, políticos e empresários, prática conhecida como "coronelismo eletrônico", que garantiu verdadeiros impérios da comunicação como a Rede Globo, ainda é utilizada no país. Fernando Henrique Cardoso (1994-2001) autorizou 357 concessões de TV's educativas sem licitação, parte considerável durante o período em que Pimenta da Veiga (PSDB-MG) ocupou o Ministério das Comunicações. Das concessões que este distribuiu, perto de 100, pelo menos 23 foram para políticos, a maioria de Minas Gerais. No Governo Lula, durante três anos e meio de seu primeiro mandato, foram aprovadas 110 emissoras educativas - 29 televisões e 81 rádios -, sendo pelo menos sete concessões de televisão e 27 de rádio para fundações ligadas a políticos (FOLHA, 2015). Diante desse quadro, podemos presumir 
que parte significativa dessas emissoras está a serviço de interesses particulares e distante de sua finalidade educacional.

\section{Mídia ou comunicação pública?}

As diversas pesquisas ${ }^{4}$ que vêm sendo desenvolvidas nos últimos anos no Brasil acerca da comunicação pública demonstram que o conceito de mídia ou comunicação pública vem ganhando maturidade, considerando as particularidades do país. Apontamos anteriormente as questões que compõem a problemática sobre o tema que apresentamos. Em nosso entendimento estas questões são centrais, mas elas se ligam também a uma perspectiva com certo comprometimento ideológico e que tornam as leituras sujeitas às diferentes conjunturas, o que colabora, a nosso ver, para uma indefinição do próprio conceito ou para diferentes interpretações que tendem a criar percepções que não dialogam com outras produções. Nesse sentido, os resultados das análises correm o risco de serem excessivamente conjunturais. Na maior parte dos casos, no entanto, o que se observa são conceitos que não estão muito claros ou que restringem o entendimento do que pode ser considerado público.

No levantamento que realizamos em busca de pesquisas que aprofundaram a questão de maneira mais contundente, observamos diferentes maneiras de conceituar o que é público na comunicação brasileira. Estas diferenças acabam diferenciando a classificação sobre os diferentes tipos de veículos radiodifusores.

Coutinho et al (2015), por exemplo, desconsidera as emissoras educativas como emissoras públicas, uma vez que o que define o caráter público de uma emissora é o seu conteúdo e não sua natureza legal ou por sua estrutura organizacional. Neste caso, poderiam ser consideradas públicas não as emissoras, mas determinados programas. Dentre eles os telejornais exibidos na TV Brasil e TV Cultura, que podem ser definidas como públicos pelo atendimento de determinados requisitos de qualidade.

Dentre os critérios estariam aqueles definidos no "I Fórum de TV's Públicas”, promovido pelo Ministério da Cultura, em 2006. Segundo Coutinho, seriam eles o aprofundamento dos temas, maior tempo de

\footnotetext{
${ }^{4}$ Em uma pesquisa publicada em 2015, apresentamos um crescimento significativo do número de trabalhos apresentados em congressos de comunicação e de livros publicados sobre o tema (CARVALHO, 2015).
} 
reportagem, notícias de interesse público, isenção de relatos, o tratamento ao telespectador como cidadão e não consumidor, além do estímulo à participação, exibição de conteúdos que não são abordados na mídia comercial, relevância para as questões de direitos humanos, representação de diferentes grupos identitários do país e pluralidade nas opiniões. Este último é considerado fundamental, uma vez que

a perspectiva de pluralidade de vozes no telejornalismo público orientaria a constituição dos programas jornalísticos em uma emissora pública como espaço para o exercício do direito à comunicação, para além do direito à informação de qualidade, aferida segundo parâmetros de excelência. (COUTINHO, 2013, p.30)

Nessa perspectiva, podem haver poucos elementos que permitam diferenciar o público do privado. Poder-se-ia, portanto, considerar como pública toda e qualquer emissora que em determinado momento exibisse um conteúdo que atendesse todos ou a maior parte destas condições, mesmo sendo elas comerciais. O rótulo "estatal" não faria sentido para fins de diferenciação entre público e privado, nesse caso.

Eugênio Bucci, que presidiu a Radiobrás e a Empresa Brasil de Comunicação (EBC) entre 2003 e 2007, advoga por um conceito mais dinâmico, porém também restrito e condicionante. A comunicação pública não "seria", ela "estaria" pública, dependendo das condições em que se encontra. O que determina o caráter público, segundo ele, seria principalmente a liberdade editorial do veículo. Esse princípio poderia estar associado à natureza estatal da emissora, mas cuja proposta de gerenciamento esteja dissociada do caráter comercial.

a emissora pública se diferencia (se afasta radicalmente) da empresa estatal na medida em que, na tradição brasileira, a emissora estatal tem seus dirigentes constituídos pelo Estado, segundo ato discricionário da autoridade estatal responsável - e, nas emissoras públicas, a indicação e a nomeação do dirigente executivo passa pela decisão de uma instância em que a sociedade civil tem representantes em maior número do que os representantes do Estado. (BUCCI, 2013, p.127)

Na busca pela melhor definição do conceito de pública e não-pública, Bucci (2015) opta pela oposição entre emissoras comerciais e não comerciais. No primeiro caso, estariam as emissoras que têm como fim o lucro, enquanto que no segundo caso estariam as emissoras públicas, as estatais e, dentro do grupo das estatais, as governamentais. 
Assim, é possível dizer que emissoras educativas podem ser consideradas públicas, pois toda emissora estatal é necessariamente pública, no sentido de estar ligada a máquina pública, mas não necessariamente no sentido de expor os interesses públicos. Seria condição para o caráter público de uma emissora "as pautas que discutem aspectos da cidadania e contribuem para fortalecer, no limite, a consciência cívica, a noção dos direitos e das liberdades." (BUCCI, 2015)

No exercício de diferenciação entre o que é público e o que é estatal, Bucci (2015) considera que o termo "emissora estatal se aplica às emissoras pertencentes ao Estado ou a ele vinculadas. A definição de emissora pública, para efeitos deste artigo, vai se aplicar às que não guardam vínculos administrativos diretos ou indiretos com o Estado." Ou seja, no caso da emissora pública, a propriedade e sua natureza jurídica não a vinculam direta ou indiretamente ao Estado. Nesse caso, se considerada a realidade atual do país, só poderiam ser consideradas públicas as emissoras comunitárias ou de universidades não federais ou estaduais, dependendo de outros aspectos, enquanto que as demais não comerciais seriam consideradas estatais, incluindo a TV Cultura ou das TV's Universitárias Federais ou Estaduais, cujo financiamento conta com recursos públicos. A diferença primordial, portanto, estaria no modelo de gestão. Para ser pública, a emissora não poderia estar subordinada a autoridades de um dos três poderes da República.

Em outras palavras, a leitura proposta por Bucci (2015) aproxima-se a de Coutinho (2013) na medida em que compreende a comunicação não como estrutura, mas como processo onde se expressam os interesses. A qualidade desse conteúdo determina a condição do processo que pode ser público ou privado. Mas Bucci vai além quando diferencia o público a partir daquele que mantém algum tipo de relação com o Estado. Essa comunicação deixa de ser pública quando não expressa a qualidade que se espera.

No livro "Sistemas públicos de comunicação no mundo", Valente et. al (2009) também trata da questão conceitual. A tradução literal de "sistema público de comunicação", por exemplo, para o inglês (public servisse broadcasting), remete a um outro significado, onde se inclui todo o sistema, seja privado ou estatal. Apesar de mais abrangente, a proposta de Valente, não inclui as modalidades de comunicação comercial. O termo adotado por ele, no entanto, é o de "mídia pública", que remete à existência de meios de comunicação de alcance massivo, e que estão em campo oposto aos meios privados. Nesse sentido, po- 
de-se dizer que ele considera público tudo o que não for privado ou que esteja movido pela lógica do lucro. Estariam inclusas nessa classificação, além da TV Cultura e a TV Brasil, as educativas, as comunitárias e a chamada governamental. Esta última poder-se-ia considerar como as de caráter estritamente institucional, como é o caso das emissoras dos poderes executivo, legislativo e judiciário. Pela lógica deste raciocínio, as emissoras universitárias, desde que ligadas a instituições públicas, poderiam, portanto, ser enquadradas no campo da mídia pública, aproximando-se das educativas, com a diferença de que tanto as governamentais, comunitárias e universitárias são exibidas, salvo raras exceções, em canais de TV fechados ou por meio digital.

Nesta proposta mais ampla de mídia pública, considera-se o caráter público não apenas aquilo que se liga a um modelo de gestão ou à qualidade dos conteúdos exibidos, mas tudo o que se liga direta ou indiretamente ao Estado e que pode ou não apresentar conteúdo de interesse público. Assim, uma emissora que se encontra em uma condição pública pode não fazer comunicação pública, entendendo a comunicação como processo. De outro lado, uma emissora privada pode emitir conteúdos públicos, mas isso não faz dessa emissora pública, justamente porque a lógica que move seus interesses é a do lucro.

Por fim, encontramos o trabalho de Zucoloto (2010) que desenvolve pesquisa com as rádios e para quem se pode considerar como emissora pública toda aquela que é não-comercial, estatal, educativa, cultural e universitária.

Embora boa parte destas emissoras tenha vinculação com o Estado, nos planos federal, estadual ou municipal, preliminarmente as observamos como inseridas no que entendemos como o grande "campo público" da radiodifusão. Aquele que abriga todas as emissoras de rádio não-comercial. Por esta compreensão, portanto, o campo público da radiodifusão brasileira inclui além destas que são nosso objeto de estudo, também as emissoras comunitárias". (ZUCOLOTO, 2010, pp. 17-18)

A questão das emissoras comunitárias é definida por ela como variável, uma vez que sua condição dependeria do cumprimento do que ela chama de "missão pública". Há, portanto, uma relação direta ou indireta com o Estado, mas também se incluiriam as iniciativas que advém da sociedade civil sem que tenham como fim o lucro, como é o caso das comunitárias. O problema é que neste caso po- 
deríamos então ampliar a abrangência do campo público inserindo, dependendo do caso, veículos ligados a igrejas, associações, clubes, sindicatos ou mesmo universidades particulares.

\section{Considerações finais}

Por comunicação pública podemos entender como uma ação monológica, que não implica na interação com o receptor. Seria, portanto, o ato de emitir ou distribuir conteúdos de caráter público, mas que não definem se uma emissora é pública ou não. É o caso da transmissão do programa do poder executivo "A voz do Brasil”, por exemplo, exibido de segunda a sexta e obrigatoriamente pelas rádios comerciais em todo o país. Trata-se de um conteúdo público institucional ${ }^{5}$, porém, exibido em veículo privado.

A partir do estudo das teorias da comunicação, Wolf (1995) descreve o conceito de mass media como aquele que se liga aos estudos da comunicação (communication research). A noção de mídia pode ter três diferentes interpretações, segundo ele, resultante dos paradigmas que guiam as pesquisas na área. Podem ser os meios de comunicação de massa, nesse caso, o veículo. A segunda conceituação decorre de cultura de massa ou sociedade de massa, a partir da leitura dos efeitos dos meios e sua capacidade de massificar o público. Wolf (1995, p. 225) encontra uma terceira definição para mass media, que se liga aos estudos de newsmaking, no qual se verifica "as determinações estruturais da cobertura informativa e da representação da realidade social". Media ou mídia, portanto, é um conceito utilizado sem unanimidade, mas se compreendido não como canal, mas como meio de comunicação e mediação da realidade entre o mundo e o indivíduo, pode ajudar a definir o ato de se comunicar para além da tecnologia. Entendemos mídia, portanto, como a expressão da ação.

Por outro lado, público refere-se à questão estruturalmente construída, sobre a natureza que define a lógica de atuação da coisa. Emitindo ou não conteúdos públicos, o veículo de comunicação resguarda um potencial público e se não cumpre esse papel está fora de seus verdadeiros propósitos. Assim, o termo "mídia pública" pode ser entendido como sendo aquele que congrega meios de comunica-

\footnotetext{
${ }^{5}$ Por institucional consideramos aqueles conteúdos que expressam informações promocionais de instituições, cujo princípio é o da defesa da mesma.
} 
ção de massa convencionais que compõem o campo público ligado direta ou indiretamente ao Estado, tendo como princípio fundamental - presente ou potencial - a mediação de informações e conteúdos, produção e emissão de conteúdos de interesse público. Enquadramse nestas condições as tv's, rádios e impressos de natureza educativa, fundacional, autárquica, estatal, governamental, institucional (órgãos de governo e empresas públicas) e universitária (de instituições de caráter público). Excluem-se, por exemplo, emissoras de organizações privadas sem fins lucrativos, como é o caso das emissoras de sindicatos, de clubes, de igrejas ou de organizações não-governamentais e, portanto, as comunitárias, que são mantidas por organizações de natureza privada, ainda que sem fins-lucrativos ${ }^{6}$.

As emissoras públicas, portanto, estão no campo da "mídia pública", podendo ou não compor um sistema a parte. O que faz delas públicas, não é o seu conteúdo, mas sua condição estrutural que representa ideologicamente uma concepção isenta e imparcial de defesa dos interesses gerais da sociedade em que o Estado é o principal vetor. É justamente o que faz da mídia pública no Brasil algo tão complexo, diverso e sujeito a interesses particulares que resultam em diferentes interpretações. Nesse sentido, um conteúdo voltado para atender aos interesses de uma elite, exibidos em uma emissora pública, não deixa de ser a expressão dos interesses de uma parcela da sociedade cujos direitos estão resguardados pela constituição do Estado e pelos valores da modernidade.

Ainda no que diz respeito à conceituação, uma das questões que precisa ser pensada é a produção em ambiente digital. Além da emissão do sinal de TV digital, há instituições públicas ou coletivos que também produzem conteúdos exclusivamente para a internet, como é o caso de rádios web e tv's web que transmitem via streaming, podcasts e videocasts, sites e redes sociais. As tecnologias digitais exigem um aprofundamento ainda maior do debate sobre o que pode ou não ser considerado mídia pública.

\footnotetext{
${ }^{6}$ Não excluímos, portanto, a possibilidade de uma emissora comunitária apresentar conteúdos públicos. No entanto, elas mantêm relações com grupos de interesses que podem ou não ser ligados à elite e, assim como no caso das emissoras comerciais e organizações da sociedade civil, têm natureza privada.
} 


\section{REFERENNCIAS}

BUCCI, Eugênio. Sobre a independência das emissoras públicas no Brasil. In: Revista Eptic. v. 15, n. 2. São Paulo: USP, 2013.

A razão de ser das emissoras públicas na democracia.

Disponível em: $<$ http://interessenacional.uol.com.br/index.php/edicoesrevista/a-razao-de-ser-das-emissoras-publicas-na-democracia/>. Acesso em: 10 jul. 2015.

CARVALHO, Guilherme. Um retrato da pesquisa em mídia pública no Brasil. In: Anais do VII Enpecom. Curitiba: UFPR, 2015. (pp.208-224)

CASTEL, R. As metamorfoses da questão social: uma crônica do salário. 2. ed. Petrópolis: Vozes, 1999.

COUTINHO, Iluska (org.) A informação na TV pública. Florianópolis: Insular, 2015.

DECRETO-Lei 236. Disponível em: <http://www.planalto.gov.br/ ccivil_03/Decreto-Lei/Del0236.htm>. Acesso em: 13 jul. 2015.

DIAGNÓSTICO do Campo Público de Televisão. In: I Fórum Nacional de Tv's Públicas: Brasília: Ministério da Cultura, 2006.

FOLHA de São Paulo. Governo Lula distribui TVs e rádios educativas a políticos. Disponível em: >http://www1.folha.uol.com.br/fsp/brasil/ fc1806200602.htm>. Acesso em: 13 jul 2015.

FRADKIN, Alexandre. História da Televisão Pública/Educativa. Disponível em: < http://fndc.org.br/download/historia-da-televisaopublica-educativa/documentos/113765/arquivo/historiatveducativa.doc $>$. Acesso em: 11 jul. 2015.

HABERMAS, J. Mudança estrutural da esfera pública: investigações quanto a uma categoria da sociedade burguesa. Rio de Janeiro: Tempo Brasileiro, 1984. 
LAVALLE, Adrián Gurza. Espaço e vida públicos: reflexões teóricas e sobre o pensamento brasileiro. Tese de doutorado. São Paulo, 2001. Programa de Pós-graduação em Ciência Política, Universidade de São Paulo.

LOPES, Maria Immacolata. Pesquisa em comunicação. $5^{\text {a }}$ ed. São Paulo: Loyola, 2001.

MELO, José Marques (org.). Comunicação na América Latina: desenvolvimento e crise. Campinas: Papirus, 1989.

ORTIZ, Renato. A moderna tradição brasileira, São Paulo: Brasiliense, 1994.

RODRIGUES, Adriano D. Comunicação e cultura: a experiência cultural na era da informação. Liboa: Presença, 1994.

SARTORI, G. Elementos de teoría política. Madri: Alianza Editorial, 2008.

SENNA, Orlando. TV pública: uma janela para o futuro do audiovisual brasileiro. In: I Fórum Nacional de Tv's Públicas: Diagnóstico do Campo Público de Televisão - Brasília: Ministério da Cultura, 2006.

SILVA, Carlos Eduardo. Muito além do Jardim Botânico: um estudo sobre a audiência do jornal nacional da globo entre trabalhadores. São Paulo: Summus, 1985.

WOLF, Mauro. Teorias da comunicação. Lisboa: Presença, 1995.

VALENTE, Jonas. Concepções e abordagens conceituais sobre sistema público de comunicação. In: Sistemas públicos de comunicação no mundo: experiências de doze países e o caso brasileiro. São Paulo: Paulus, Intervozes, 2009.

ZUCULOTO, Valci. A construção histórica da programação de rádios públicas brasileiras. Porto Alegre, PUCRS, 2010. Tese de doutorado no Programa de Pós-graduação em Comunicação da FAMECOS. Porto Alegre, PUCRS, 2010. 
AÇÃO MIDIÁTICA, n.11. Jan/jun. 2016. Curitiba. PPGCOM-UFPR. ISSN 2238-0701

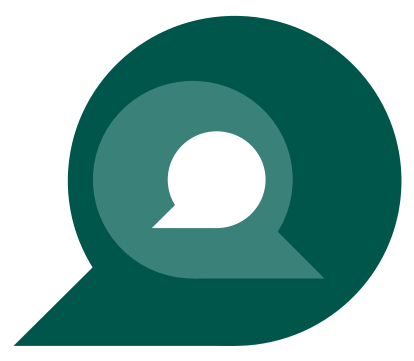

